\title{
Reframing urban "wildlife" to promote inclusive conservation science and practice
}

\author{
Monika Egerer ${ }^{1,2}$ (D) Sascha Buchholz $z^{2,3}$
}

Received: 17 October 2020 / Revised: 2 February 2021 / Accepted: 12 April 2021 / Published online: 19 April 2021 (c) The Author(s) 2021

\begin{abstract}
Cities are home to both a majority of the world's human population, and to a diversity of wildlife. Urban wildlife conservation research and policy has importantly furthered ecological understanding and species protection in cities, while also leveraging wildlife conservation to connect people to urban nature. Thus, urban wildlife conservation intersects conservation research, conservation policy, and the general public in cities worldwide. Yet, species that are often framed as "urban wildlife" are often of higher trophic levels, including birds and mammals that serve as "flagship" species for public support. Other forms of urban life including plants and invertebrates are often largely ignored, producing a normative urban wildlife concept that may bias urban wildlife conservation research and policy, and sentiment in the general public. To develop new strategies in urban wildlife conservation for the urban era, we need to move towards a more inclusive and holistic framing of urban wildlife for both research and the public. In this article, we discuss the normative framing of urban wildlife and how this framing may bias urban conservation efforts, and argue for a holistic approach to urban wildlife inclusive of all life forms for future research, publicity and policy interventions.
\end{abstract}

Keywords Conservation · Ecology $\cdot$ Human-wildlife interactions · Urban · Wildlife

Communicated by Dirk Sven Schmeller.

Monika Egerer

monika.egerer@tum.de

Sascha Buchholz

sascha.buchholz@tu-berlin.de

1 School of Life Sciences, Technical University of Munich, Hans Carl-von-Carlowitz-Platz 2, 85354 Freising, Germany

2 Department of Ecology, Technical University of Berlin, 12165 Berlin, Germany

3 Berlin-Brandenburg Institute of Advanced Biodiversity Research (BBIB), 14195 Berlin, Germany 


\section{Introduction}

Many of the world's growing cities are located in biodiversity rich areas, or "biodiversity hotspots" (Ives et al. 2016). Rapid urbanization often drives declines of biodiversity in many regions and has catalyzed wildlife conservation strategies and efforts designed for cities. Most urban wildlife conservation efforts by researchers and policymakers focus on charismatic species, specifically vertebrates. For example, urban conservation actions include: protection of urban forest fragments, provision of green bridges and wildlife corridors for birds and large carnivore populations (Riley et al. 2014); wildlife-friendly gardens for hedgehogs and bats to 're-wild' urban areas (Van Helden et al. 2020); and citizen science urban wildlife conservation research programs monitor urban bird (e.g., 'Celebrate Urban Birds' program) and wild fox populations (Scott et al. 2014). As such, these familiar and charismatic fauna species of birds and mammals are often what people associate with urban 'wildlife' conservation or management particularly among the general public. Why are such vertebrate species framed as 'urban wildlife', while others including plants, fishes and arthropod invertebrate species are rather framed and labeled as 'urban biodiversity'? What may this imply for invertebrate conservation if 'urban wildlife' serves as a synonym for higher trophic level flagship species popular with the public?

Here, we question the normative framing of 'urban wildlife' particularly in the context of invertebrate conservation practice in cities. We focus specifically on urban wildlife conservation because, as an emerging interdisciplinary field, conservation efforts and programs are designed and implemented differently in cities to integrate people, the environment, and their interactions (Shwartz et al. 2014). Urban wildlife conservation faces unique challenges arising from the spatial heterogeneity of urban ecosystems (e.g., extreme habitat fragmentation and degradation) and environmental stressors (e.g., light pollution, soil quality, transport infrastructure) combined with the social context around nature and conservation in cities (e.g., loss of nature experience, people's perceptions of and connection to nature, to wildlife; (Miller 2005)). Moreover, urban residents may be biased towards certain facets of urban wildlife and their common perception of ecosystem service provision (Home et al. 2009). This can stifle comprehensive biodiversity conservation if people are unwilling to support conservation efforts towards what they may not perceive as wildlife (Soanes et al. 2019). It is within this context that we consider the potential impact of a normative 'urban wildlife' framing for citizens, researchers or practitioners if-though aims are shared (e.g., protecting biodiversity in urban environments; promoting ecosystem function and services; fostering human-wildlife experiences in cities) - this may bias urban conservation efforts (especially for invertebrates) with unforeseen consequences on ecosystem-level conservation and ecosystem service provision.

\section{What associates with urban "wildlife"?}

Urban wildlife has its associations in scientific research and among the general public. Academic and applied perspectives tend to focus predominantly on urban 'wildlife' as higher trophic level vertebrate populations including mammals and birds, while plants and invertebrates are both largely ignored as urban 'wildlife' (Magle et al. 2012), or are distinguished from urban wildlife (Adams 2005). In Magle and colleague's search of the literature using the word urban "wildlife", less than $10 \%$ of recent papers included a study 
about plants or arthropods (Magle et al. 2012). This discrepancy is further highlighted in our review of the recent literature of three high impact conservation journals (Conservation Letters, Conservation Biology, and Conservation Science and Practice). A review of the years 2019 and 2020 using 'wildlife' as a search term in any field identified 348 studies, of which only six included arthropods. In an analysis of ten urban wildlife conservation programs, only one included insects to a minimal extent (Bern, Switzerland: two species out of 71 species in total). This is not to say that, for example, urban arthropod research does not exist, as there are many arthropod studies in cities (Beninde et al. 2015; Fenoglio et al. 2020). However, this framing in scientific research can shift the focus of conservation efforts or programs because arthropod research is in most cases not framed as wildlife research. Moreover, in the 2019 Urban Wildlife Conference, most work continues to focus on mammals and birds as focal species, with very few on invertebrates, including bees. The oversight can create a gap or bias in scientific knowledge if literature searches and scientific exchange focus on wildlife largely excluding invertebrates. Science mimics paradigms in society and the general public of what is synonymous with 'wildlife': searching 'urban wildlife' in Google Images similarly reveals only two of 300 photos with invertebrates.

A mammalian and bird focus in urban 'wildlife' research and practice follows academic disciplinary traditions in wildlife conservation research where wild game management laid the foundation for the discipline of urban wildlife ecology, conservation, and management in the late 1960s and 1970s (Adams 2014). This set course for using the term wildlife for animals that can be hunted, and while hunting game is uncommon in cities, the term wildlife still seems to be used with traditional meaning. Yet, as defined by Cambridge, "wildlife" should holistically consider "animals and plants that grow independently of people, usually in natural conditions" (Cambridge Dictionary 2020). This English definition translates similarly to "wildlife" definitions and concepts in many other languages, from Portugese (vida selvage; "all plants, fungi and other organisms that grow or live wild in an area without being introduced by humans") to Chinese (野生动植物; “all kinds of undomesticated animals that live in their natural state and have not been subjected to artificial selection") (Appendix 1). The urban environment inherently complicates these definitions (i.e., what is 'natural' in cities). Yet in principle, urban wildlife should consider spontaneous unmaintained vegetation populating urban forest fragments harboring silvicolous insects; unmanaged long-naturalized neophyte plants providing habitat for invertebrates in urban dry grasslands; and wild pollinating insects roaming urban gardens and streetscapes. All of these wild species are central agents to urban ecosystem function including nutrient cycling, decomposition, and pollination. Moreover, city dwellers come into contact with these lifeforms just as often, if not more, in their daily lives than with those lifeforms that are currently emphasized as urban wildlife: most people likely encounter insects more frequently than bats in cities. The emphasis of particular taxa within urban environments as urban 'wildlife' opens a debate on how this framing may bias urban conservation research and practice, especially against the background of an alarming worldwide insect crisis (Hochkirch 2016) and the understanding that cities can be hotspots for threatened invertebrate species (Soanes and Lentini 2019).

We confront the focus on higher trophic levels and "mega-fauna" in the conceptualization and application of the urban wildlife frame in scientific research but also in the general public. This as a technically incorrect framing of what is actually 'wild' life in cities. Studies on plants and invertebrates in urban areas have long contributed to our understanding of the ecology of urban environments, the flora and fauna therein, and the important role of such species for urban ecosystem function and services (Wu 2014). Why are such species not necessarily framed as urban wildlife in the scientific community, but rather framed 
and labeled as 'urban biodiversity' — which can be difficult to understand for some urban residents, and not necessarily synonymous with 'wildlife' (Levé et al. 2019). What sense in conservation research and practice does it make to label, for example, urban bats as 'urban wildlife' but urban bumblebees as 'urban biodiversity'? Both labels may evoke different meanings to researchers and city residents, and how the public perceives a species can largely affect what is considered acceptable in species management and conservation (van Eeden et al. 2020). It is concerning that 'urban wildlife' may not necessarily involve wild plants or invertebrates in urban environments, with wildlife ecology historically separating wildlife into "wildlife and plants" (Adams 2005). What are the conservation implications in policy and practice if 'urban wildlife', rather than biologically correct, serves as a synonym for iconic flagship species popular with the general public? How will this influence the acceptance of conservation programs in the general public?

Overlooking plants, invertebrates, amphibians, and lower trophic levels as urban wildlife can influence public perception and public willingness to contribute to the conservation of these taxa, with city dwellers more willing to protect charismatic megafauna flagship species above all (Mesquita et al. 2014; Colléony et al. 2017; Curtin and Papworth 2020). Although invertebrates are essential to urban ecosystem functioning (McIntyre 2000), arthropods are often dismissed as harmful pests or a nuisance in cities-associated with filth and sickness by residents - and not prioritized in urban wildlife conservation (Hunter and Hunter 2008). Yet, because such trophic levels or dimensions of urban wildlife are often what people experience daily, people may be more likely to value invertebrates and plants in urban conservation efforts if such life forms are framed as urban wildlife. A shift in perceptions, values, and norms around urban wildlife especially in publicity is critical for urban invertebrate conservation to ultimately influence habitat management and urban conservation financial support (Schultz and Kaiser 2012). For example, insects that are "buglike" and less "human-like" are often perceived as less attractive, less worthy of rescue than other animals among the general public (Cardoso et al. 2011; Mesquita et al. 2014), and thereby receive less conservation funding (Curtin and Papworth 2020). How can we shift negative perceptions of invertebrates among the general public to equally value such creatures as ecosystem service providers, as they may for larger mammals or birds? What is the conservation potential if spaces such as urban gardens can facilitate more positive, and less negative interactions with less charismatic species?

This presents a new opportunity to rethink the urban wildlife framing in conservation science, practice, and science-society interfaces. It is time for an inclusive framing of urban wildlife, a holistic urban wildlife concept, to deepen the ecological understanding of urban ecosystems, and to heighten society's appreciation of all urban wildlife across all life forms. An inclusive framing could best promote more diverse and holistic species conservation and protection in cities. We frame urban wildlife to include all trophic levels and life forms within urban ecosystems, from soil-dwelling organisms, invertebrates, small mammals, and large carnivores (Fig. 1). Within this inclusive frame, urban wildlife should, in principle, also encompass un-managed non-native neophyte species long naturalized. What species we then deem of conservation concern and action can then be in question for practitioners and policymakers (e.g., debates about conserving non-natives). But painting a false image or perpetuating a normative narrative about what comprises urban wildlife in research but more importantly also in the general public can have adverse conservation outcomes if, for example, we neglect other trophic levels and less charismatic species that are necessary for ecosystem functioning because public support for targeted conservation is absent. An inclusive urban wildlife framing in public awareness campaigns is especially important in times of rapid invertebrate 


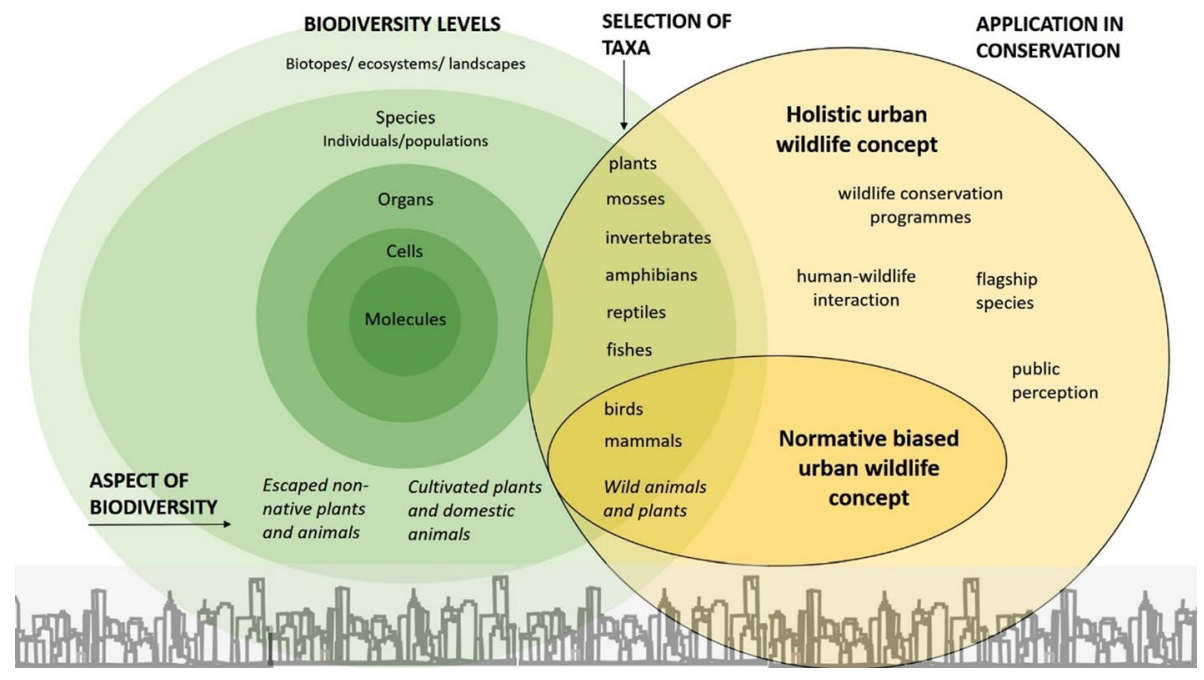

Fig. 1 Although the basic unit of biodiversity is often the species, biologically speaking it consists of several levels, from molecules to biotopes. In urban areas, species are therefore only one aspect of biodiversity, but the essential benchmark for the wildlife concept. However, in both urban conservation research and conservation policy the selection of relevant taxa is then determined by the underlying wildlife concept, and whether we apply a biased wildlife framing or a holistic wildlife framing. This framing determines whether we consider only a part of all wild living plants and animals or all of them. The framing in turn may affect which taxa of biodiversity come into the focus of urban "wildlife" conservation programs, are selected as flagship species, or are the subject of public perception

biodiversity loss, growing cities, and the heightening interest in and importance of urban arthropod conservation This can be achieved, for example, through popular science books and brochures that inspire the public about invertebrates and their ecological importance, according to Heinz Sielmann's motto "Only those who know nature will protect it".

Some national-level wildlife organizations are beginning to explicitly recognize, for example, native insect pollinators in their framing and programs, such as in the US (e.g. the National Wildlife Foundation; https://www.nwf.org/Our-Work/Wildlife-Conservation) and in Europe (e.g. the German Wildlife Foundation; https://www.deutschewildtierstiftung. de/wildtiere). Moreover, recent successful urban wildlife programs are using other trophic level species as a "mascot" for their wildlife programs, with great potential to deconstruct the image of wildlife as only birds and mammals within the general public. For example, the German Wildlife Foundation is using bumblebees as flagship species. We need to expand such inclusivity in urban conservation practice and policy across trophic levels and life forms to appreciate and conserve wildlife within urban environments worldwide. This includes going beyond including charismatic native bee and butterfly pollinators to elevate plants, fishes, and even "creepy crawlies" like spiders both in conservation research and science communication to the general public. Urban biodiversity conservation requires a particular publicity approach because most urban dwellers have unique perspectives and connections with nature (Berenguer et al. 2005). We provide three lines of evidence to support this argument. 


\section{Argument 1: promoting inclusive urban conservation science}

A holistic urban wildlife framing is essential to understand the biological mechanisms underpinning urban ecological communities, and how environmental change affects species identity, composition, traits, and interactions in all life forms, trophic levels, and ecological functions-not only the last segment of trophic chains. Urban ecosystems are complex systems in which species assembly and species filtering are dually shaped by environmental and anthropogenic filters (Aronson et al. 2016). Invertebrates quickly respond to abiotic and biotic change in urban environments, serving as bioindicators or early-warning organisms with implications for higher trophic levels such as birds (McIntyre 2000). While there are many examples of urban studies that focus on invertebrates and plants, this work may not come up in a search for papers on 'urban wildlife'. This may impair understanding of urban ecosystem function but also suggests missing the first impacts of environmental change on what is still largely considered urban wildlife. For example, conservation biologists and landscape planners designing urban corridors for wildlife predominantly focus on birds, deer, and small mammals. There is very limited information on how urban wildlife corridors affect invertebrate, amphibian, or reptile species (Riley et al. 2014). Yet, by the time this invertebrate biodiversity loss is realized, it may be too late. An inclusion of invertebrates as urban wildlife is important for furthering urban ecological theory, species conservation, and habitat to landscape management. Also, the increasing numbers of conferences and programs focusing on urban wildlife (e.g. Urban Wildlife Conference) and human-wildlife interactions (e.g. Pathways Conference) should explicitly encourage other trophic level urban research in their programs.

\section{Argument 2: fostering urban nature experiences and genuine human-wildlife understanding in the general public}

Incorporating all aspects of wildlife in social perspectives of urban wildlife is key to heighten the quality and quantity of human-wildlife interactions in cities, as many city residents experience plants and invertebrates every day, even on their balconies and garden terraces. The extinction of wildlife or 'nature' experiences over recent decades in society (Cox et al. 2017) has heightened the importance of increasing urban society's 'biophilic' engagement with natural elements and biodiversity for public health and wellbeing (Morris 2003). Many people engage with urban nature by digging in microbially diverse soils while urban gardening, walking a dog, or sitting in a park. Observing ladybugs in a garden, sniffing wildflowers in a pocket prairie, foraging for wild plants in remnant forests, and touching emerged slimy earthworms after a spring rain are all simple biophilic interactions between urban residents and their (semi-)natural urban environment. Just as these actions encompass multiple senses of human's physiological capacity to sense the world, all involve urban human-wildlife biophilic interactions across trophic levels of urban ecosystems. Increasing biophilic interactions and the ecological literacy of urban human populations requires experience with and understanding of multiple trophic levels and different life forms of urban wildlife, not only charismatic fauna but also the flora that set the stage for species interactions-including those of Homo sapiens via urban human-wildlife experiences. But we are still lacking in our understanding of the diverse benefits that living with urban wildlife can bring (Soulsbury and White 2015). A holistic urban wildlife framing 
beyond 'flagship' species communicated to urban residents in conservation education programs or research could foster a more genuine appreciation and understanding of urban wildlife across life forms. Here, public awareness campaigns can play a key role to debunk negative perceptions and shift the narrative to place uncharismatic creatures at the same level as larger mammals and birds.

\section{Argument 3: an applied conservation perspective}

Biases in urban wildlife research may hinder our ability to best manage invertebrate and plant species conservation under urbanization. Conservation biology and wildlife research are traditionally framed as a holistic science with a systems-level perspective (Soule 1985). Yet the framing, research focus, and subsequent conservation priorities in wildlife research and conservation planning are disproportionately aimed at megafauna and charismatic mammal and vertebrate species at higher trophic levels (Clucas et al. 2008). The debate on the role of charismatic species or "flagship" species in conservation protection has highlighted the flaws of charisma and a higher trophic level focus in realizing conservation outcomes (Nakamura 2018). In cities, the use of "wildlife" may function as a synonym for flagship species that work as iconic symbols to stimulate public and policy support for research and conservation action, regardless of ecological function (Home et al. 2009). Urban wildlife conservation programs should frame all trophic levels and diverse life forms in management programs as urban wildlife to maximize conservation action. For example, species such as urban-restricted threatened endemic plants have great potential to be flagship species by leveraging local community pride and sense of place (e.g. urban Australia's Canberra spider-orchid illustrated by Soanes and Lentini (2019)). If framed as such, urban wild insect pollinators in gardens and parks could also be excellent flagship species for urban wildlife conservation due to the diverse ecosystem services they provide (Fortel et al. 2016). An inclusive framing of all wildlife in cities is important to best manage and protect all species critical for maintaining ecosystem functions and ecological network stability.

\section{Conclusion}

Strong urban conservation policy and programs combined with better human-wildlife relationships are essential to further global biodiversity conservation priorities. Cities are where a majority of the world's population experience wildlife, particularly in its untraditional and uncharismatic forms. The contemporary urban era requires moving beyond normative associations of what is wild in cities both in research and in public perceptions to a more holistic framing of what we consider, value, and thereby conserve as urban wildlife. We support:

- Equal consideration of species in frames of urban wildlife according to ecological functions and ecosystem services (e.g., pollination, decomposition, contributions to human well-being, etc.).

- An understanding of conservation science and policy that wildlife is a part of biodiversity and both terms cannot be used to describe a selection of species.

- Urban conservation programs on flagship species including Citizens Science approaches that extend to all taxa, technically and financially, to focus the attention of 
city dwellers to invertebrates_-"the little things that run the world" (Wilson 1987)—as valuable facets of urban "wildlife" and as excellent surrogate species.

Inclusion of all life forms across trophic levels-soil microorganisms, plants, invertebrates, and others - in the framing of urban wildlife will deepen our understanding of urban ecosystem processes, promote unbiased conservation action, and create genuine human-nature experiences with the diversity of wildlife in cities. With this conclusion, we invite responses from researchers and practitioners working in this space. We welcome agreement and disagreement, but more importantly productive ideas on how to deconstruct normative perceptions around urban wildlife in the scientific literature and in the general public through innovative research approaches and science communication. Let us engage in this dialogue that sits at the intersection between science and society to further broaden the conservation potential of all wild life within urban areas.

\section{Appendix 1}

Definitions of wildlife from different languages most spoken across the world. All definitions were taken from the language-specific Wikipedia pages The translations were done by the authors with support from DeepL and the Google Translator.

\section{Spanish}

\section{Fauna silvestre}

These are all those animals that live in the wild without receiving any direct help from man to obtain their needs (food, reproductive partners, shelter, water etc.). All organisms are included, from the smallest invertebrates to the largest vertebrates. Wildlife is also perceived as the animals whose evolutionary development occurred and continues to occur without the direct or indirect intervention of humans. Humans do not intervene in aspects such as the adaptations of species to the geographical and climatic conditions of their habitats.

\section{Vida silvestre}

Wildlife refers to all plants, animals, fungi, and other undomesticated organisms that inhabit a place without being introduced by humans.

\section{French}

\section{La faune (no other term available)}

The term fauna refers to all the animal species present in a given geographical area or ecosystem (as opposed to flora) at a given time. 


\section{Italian}

\section{Fauna selvatica (no other term available)}

The fauna is made up of all the species and animal populations, vertebrates and invertebrates, resident in a given territory and included in its ecosystems; it can include autochthonous species and immigrant species that have become indigenous, as well as species introduced by man that have become indigenous.

\section{Portuguese}

\section{Vida selvagem}

Wildlife is traditionally understood as the non-domesticated animal species, but now includes all plants, fungi and other organisms that grow or live wild in an area without being introduced by humans.

\section{Russian}

\section{дикая природа [dikaya priroda]}

Wilderness is an ecological term for nature in its natural state, undisturbed by human activities; areas of nature untouched by humans and largely uncontrolled by humans, where native biodiversity and ecosystem processes are maintained and little man-made non-living nature exists (cliffs, mountains, water bodies etc.). In these areas, wildlife reproduces naturally, maintaining self-regulation through internal processes. A wilderness area can also act as a cultural landscape to some extent, with an aboriginal people living in the area for many years.

\section{Chinese}

\section{野生动植物}

Wildlife refers to all kinds of undomesticated animals that live in their natural state and have not been subjected to artificial selection. Depending on the country and the international body, this may or may not include abandoned and feral domesticated animals as well as captive animals. 


\section{Swahili}

\section{Wanyamapori}

Wild animals are wild animals and are not domesticated by humans like other animals.

\section{Bahasa}

\section{Hidupan liar}

Wild life is a species of wild animal or wild bird, whether fully protected or protected, vertebrates or invertebrates, live or dead, mature or immature.

\section{German}

\section{Wildtiere}

A wild animal or wild animal is an animal living in the wild that does not serve humans as a domestic, farm or breeding animal and is therefore not domesticated. Animals living in settled areas, nested in buildings or even parasitic animals are wild animals, although they do not live in the wild proper, but retain the lifestyle of a wild animal. Basically, any animal apart from humans can be a wild animal. The same principle for plants is represented by wild plants.

Acknowledgments We thank Svea Rogge for the design of Fig. 1 and Tanja Straka for valuable comments on the manuscript. Thank you to two anonymous reviewers for comments that significantly improved the manuscript. SB was funded by the German Federal Ministry of Education and Research BMBF within the Collaborative Project "Bridging in Biodiversity Science-BIBS" (funding number 01LC1501A-H). ME was funded by the International Postdoc Initiative of the TU Berlin.

Author contribution All authors have made substantial contributions to the conception, design, and drafting of the manuscript. ME led the writing of the manuscript. All authors approve of the version to be published.

Funding Open Access funding enabled and organized by Projekt DEAL.

\section{Declarations}

Conflict of interest The authors declare that they have no known potential sources of conflict of interestnor competing financial interests or personal relationships-that could have appeared to influence the work reported in this paper.

Impact statement Effective conservation research and policy interventions for the urban era require inclusive, unbiased framings of all life as urban wildlife.

Open Access This article is licensed under a Creative Commons Attribution 4.0 International License, which permits use, sharing, adaptation, distribution and reproduction in any medium or format, as long as you give appropriate credit to the original author(s) and the source, provide a link to the Creative Commons licence, and indicate if changes were made. The images or other third party material in this article are included in the article's Creative Commons licence, unless indicated otherwise in a credit line to the 
material. If material is not included in the article's Creative Commons licence and your intended use is not permitted by statutory regulation or exceeds the permitted use, you will need to obtain permission directly from the copyright holder. To view a copy of this licence, visit http://creativecommons.org/licenses/by/4.0/.

\section{References}

Adams LW (2005) Urban wildlife ecology and conservation: a brief history of the discipline. Urban Ecosyst 8:139-156. https://doi.org/10.1007/s11252-005-4377-7

Adams LW (2014) History of urban wildlife conservation. In: Urban Wildlife Conservation: Theory and Practice. Springer, NewYork, pp 11-31

Aronson MFJ, Nilon CH, Lepczyk CA et al (2016) Hierarchical filters determine community assembly of urban species pools. Ecology 97:2952-2963

Beninde J, Veith M, Hochkirch A (2015) Biodiversity in cities needs space: a meta-analysis of factors determining intra-urban biodiversity variation. Ecol Lett 18(6):581-592. https://doi.org/10.1111/ ele. 12427

Berenguer J, Corraliza JA, Martin R (2005) Rural-Urban differences in environmental concern, attitudes, and actions. Eur J Psychol Assess 21:128-138. https://doi.org/10.1027/1015-5759.21.2.128

Cambridge Dictionary (2020) WILDLIFE I meaning in the Cambridge English Dictionary. https://dicti onary.cambridge.org/dictionary/english/wildlife. Accessed 21 Apr 2020

Cardoso P, Erwin TL, Borges PAV, New TR (2011) The seven impediments in invertebrate conservation and how to overcome them. Biol Conserv 144:2647-2655. https://doi.org/10.1016/j.biocon.2011.07.024

Clucas B, McHugh K, Caro T (2008) Flagship species on covers of US conservation and nature magazines. Biodivers Conserv 17:1517-1528. https://doi.org/10.1007/s10531-008-9361-0

Colléony A, Clayton S, Couvet D et al (2017) Human preferences for species conservation: animal charisma trumps endangered status. Biol Conserv 206:263-269. https://doi.org/10.1016/j.biocon.2016.11.035

Cox DTC, Hudson HL, Shanahan DF et al (2017) The rarity of direct experiences of nature in an urban population. Landsc Urban Plan 160:79-84. https://doi.org/10.1016/j.landurbplan.2016.12.006

Curtin P, Papworth S (2020) Coloring and size influence preferences for imaginary animals, and can predict actual donations to species-specific conservation charities. Conserv Lett. https://doi.org/10. $1111 /$ conl.12723

Fenoglio MS, Rossetti MR, Videla M (2020) Negative effects of urbanization on terrestrial arthropod communities: a meta-analysis. Glob Ecol Biogeogr 29(8):1412-1429. https://doi.org/10.1111/geb.13107

Fortel L, Henry M, Guilbaud L et al (2016) Use of human-made nesting structures by wild bees in an urban environment. J Insect Conserv 20:239-253. https://doi.org/10.1007/s10841-016-9857-y

Van Helden BE, Close PG, Steven R (2020) Mammal conservation in a changing world: can urban gardens play a role? Urban Ecosyst 23:555-567. https://doi.org/10.1007/s11252-020-00935-1

Hochkirch A (2016) The insect crisis we can't ignore. Nature 539:141

Home R, Keller C, Nagel P et al (2009) Selection criteria for flagship species by conservation organizations. Environ Conserv 36:139-148. https://doi.org/10.1017/S0376892909990051

Hunter M, Hunter MD (2008) Designing for conservation of insects in the built environment. Insect Conserv Divers 1:189-196

Ives CD, Lentini PE, Threlfall CG et al (2016) Cities are hotspots for threatened species. Glob Ecol Biogeogr 25:117-126. https://doi.org/10.1111/geb.12404

Levé M, Colléony A, Conversy P et al (2019) Convergences and divergences in understanding the word biodiversity among citizens: a French case study. Biol Conserv 236:332-339. https://doi.org/10. 1016/j.biocon.2019.05.021

Magle SB, Hunt VM, Vernon M, Crooks KR (2012) Urban wildlife research: past, present, and future. Biol Conserv 155:23-32. https://doi.org/10.1016/j.biocon.2012.06.018

McIntyre NE (2000) Ecology of urban arthropods: a review and a call to action. Ann Entomol Soc Am 93:825-835. https://doi.org/10.1603/0013-8746(2000)093[0825:EOUAAR]2.0.CO;2

Mesquita PCMD, Lipinski VM, Polidoro GLS (2014) Less charismatic animals are more likely to be "road killed": human attitudes towards small animals in Brazilian roads. Biotemas 28:85. https:// doi.org/10.5007/2175-7925.2015v28n1p85

Miller JR (2005) Biodiversity conservation and the extinction of experience. Trends Ecol Evol. https:// doi.org/10.1016/j.tree.2005.05.013

Morris N (2003) Health Well-Being and Open Space Literature Review. OPENspace Research Centre, Edinburgh 
Nakamura F (ed) (2018) Biodiversity conservation using umbrella species. In: Ecological research monographs. Springer, Singapore. ISBN 978-981-10-7202-4

Riley SPD, Brown JL, Sikich JA et al (2014) Wildlife friendly roads: the impacts of roads on wildlife in urban areas and potential remedies. In: Urban Wildlife Conservation: Theory and Practice. Springer, US, pp 323-360

Scott DM, Berg MJ, Tolhurst BA et al (2014) Changes in the distribution of red foxes (Vulpes vulpes) in urban areas in Great Britain: findings and limitations of a media-driven nationwide survey. PLoS ONE 9:e99059. https://doi.org/10.1371/journal.pone.0099059

Shwartz A, Turbé A, Julliard R et al (2014) Outstanding challenges for urban conservation research and action. Glob Environ Chang 28:39-49. https://doi.org/10.1016/j.gloenvcha.2014.06.002

Soanes K, Lentini PE (2019) When cities are the last chance for saving species. Front Ecol Environ 17:225-231. https://doi.org/10.1002/fee.2032

Soanes K, Sievers M, Chee YE et al (2019) Correcting common misconceptions to inspire conservation action in urban environments. Conserv Biol 33:300-306. https://doi.org/10.1111/cobi.13193

Soule ME (1985) What is conservation biology? Bioscience 35:727-734

Soulsbury CD, White PCL (2015) Human-wildlife interactions in urban areas: a review of conflicts, benefits and opportunities. Wildl Res 42:541-553. https://doi.org/10.1071/WR14229

van Eeden LM, Newsome TM, Crowther MS et al (2020) Diverse public perceptions of species' status and management align with conflicting conservation frameworks. Biol Conserv 242:108416. https://doi. org/10.1016/j.biocon.2020.108416

Wilson EO (1987) The little things that run the world (the importance and conservation of invertebrates). Conserv Biol 1:344-346

Wu J (2014) Urban ecology and sustainability: the state-of-the-science and future directions. Landsc Urban Plan 125:209-221. https://doi.org/10.1016/j.landurbplan.2014.01.018

Publisher's Note Springer Nature remains neutral with regard to jurisdictional claims in published maps and institutional affiliations. 